
and Aromatic Plants

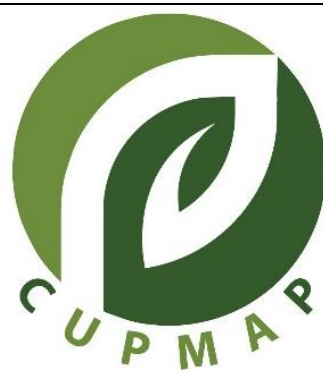

\title{
Poisonous Plants for Cats and Dogs Kept in House 1: Dieffenbachia spp., Melia azedarach, Ricinus communis, Euphorbia pulcherrima, Narcissus spp.
}

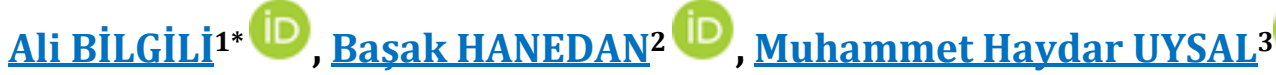

\author{
${ }^{1}$ Department of Pharmacology and Toxicology, Faculty of Veterinary Medicine, University of Ankara, \\ 06110, Ankara, TURKEY \\ *Corresponding author: abilgili@gmail.com \\ 2Department of Internal Medicine, Faculty of Veterinary Medicine, University of Ataturk, \\ 25240, Erzurum, TURKEY, E-mail: fbhanedan@gmail.com \\ ${ }^{3}$ Department of Pharmacology and Toxicology, Health Sciences Institute, Ankara University, \\ 06110, Ankara, TURKEY, E-mail:uysalhaydar@hotmail.com
}

\begin{abstract}
Poisonous plants are responsible for many poisoning events. These plants are commonly grown in homes and gardens and are eaten by dogs and cats. In this context, it was dealt with poisonous effects of especially Dieffenbachia spp., chinaberry tree (Melia azedarach), castor bean (Ricinus communis), poinsettia (Euphorbia pulcherrima) and daffodil (Narcissus spp.) from plants leading to poisoning, grown commonly in parks, gardens, and homes, in our country. The plant species leading to poisoning for both dogs and cats were presented in table. In addition, comprehensive information was presented on their adverse effects in different organ and tissues occurring in the result that they are eaten by dogs and cats, their clinical signs, and their treatments. The concise knowledge was given on the required measures for preventing poisoning of animals kept in home with these plants in also our country, as in world countries.
\end{abstract}

Key Words: Dogs, cats, poisonous plants

(C) CUPMAP. All rights reserved.

\section{Introduction}

Severe poisonings occur in the result that dogs and cats eat these plants with increase of import hall plants and ornamental plants, and together with widespread landscape design of house, office, and garden, and increased domestic cat and dog population also in our country, as all over the world. In USA, it is reported that $12 \%$ of poisonings of cats and dogs kept in house are caused by plants (Mahdi and van der Merwe, 2013). Indoor plants as a part of trade sector are used commonly for esthetic and functional features in living spaces. As a result that poisonous plants are present commonly in places such as apartment, house, office, and shopping center, pet animals chew or eat these plants and intoxications occur (Tiwari and Sinha, 2010).

Dogs and cats can show behaviour to put them into their mouths and to chew leafs, stems, flowerings and seeds of plant due to various reasons, especially getting bored in restraint area when the owner is not in the house, curiosity, and dentition in young 
animals (Botha and Penrith, 2009; Tiwari and Sinha, 2010).

Plant eating, especially grass eating, is commonly appeared in all domestic cats and dogs, and to vomit when they feel ill themselves (to recover the gastric problems or gastrointestinal parasites) or because of dietary deficiencies or as general behavior, they eat plants. In this condition, it is appeared in not only dogs kept in house and in but also wolves and other wild dog species (Sueda et al., 2008). Tendencies of cats to eat plants are less than those of dogs (Sueda et al., 2008). In a study made by Sueda et al. (2008), it has been reported that $79 \%$ of well-kept healthy dogs eat grass, eating plant in domestic dogs is a behaviour commonly seen, and also that dogs are appeared normal before eating plant and $87 \%$ of dogs do not vomit after eating plant.

Poisonous plants include primary substances (carbohydrate, organic acids, and amino acids) required to be able to maintain main metabolisms, and secondary substances (alkaloids, glycosides, oxalates, resinous compounds, tannins, and volatile oils) generated as byproducts during main metabolisms. Major parts of secondary substances have toxic effects to humans and animals (Yılmaz et al., 2006). Toxic properties of some of these plants commonly used in landscaping of indoor and outdoor places are not known. To be eaten by cat, dog and other domestic animals can cause from simple clinical signs such as vomiting, diarrhea, dermal problems to negative effects such as deaths. Severity of poisoning with plants can vary according to the factors related to plant (species, region, consumed amount, parts of plant, its growth stage, etc.) and animal species (age, health condition, etc.) (Anadon et al., 2012). The toxicity of plant varies according to the season, climate, soil, and geographical area (Panter et al., 2013). In addition, sensitivity to poisonous plant may show variations specific to species or among individuals of same species (Anadon et al., 2012). For these reasons, plants to be used in the landscaping should not be considered with only ecological, economics and esthetic features. Thus, toxicity features of indoor and outdoor ornamental plants located in living places should be also known.

Generally poisoning of dogs and cats kept in house by plants occurs via eating plant, exposure to plant, photosensitivity, flavoring and odour with by-products, and mechanical damage. In poisoning of dogs and cats with plants, factors belonging to plant consist of soil, climate, growth stage, parts of plant, and health of plant. Animal factors consist of natural immunity, alimentary system, acquired immunity, breed, age, nutrition, gender, and dependency conditions.

By dealing with toxicities of several indoor and outdoor ornamental plants involved in all society and shared in living places and their adverse effets to dogs and cats in this study, uses of plants were aimed to take attention. In dogs and cats, some of the most plants leading to poisoning were presented in Table 1.

\section{Poisonous plants}

\subsection{Dieffenbachia spp.}

Characteristics and resources: They are of the most dangerous and wide plant groups comprising many toxic components. These plants can reach a height of up to $2 \mathrm{~m}$ and of 1-1.5 $\mathrm{m}$ in an appropriate environment in house. This plant is perennial and evergreen. It is grown as ornamental plant in house due to easy maintenance (Cortinovis and Caloni, 2013; Akça et al., 2014).

Toxic components: The plant contains saponins, alkaloids, cyanogenic glycosides, proteoliytic enzymes, calcium oxalate crystals and oxalic acid. The plant sap is poisonous. The main cause of poisoning is calcium oxalate crystals, oxalic acid, and protease irritating mucosa and releasing histamin. The stems and leaves of dumb cane like other members of the Araceae 
family contain clusters of long and needlelike calcium oxalate crystals called raphides. Raphides are packed in specialized cells called idioblasts and released outside the cell if the plant is damaged (e.g., chewing, rubbing or cutting off the leaves). If raphides are embedded in mucosa, they entail extensive irritation and inflammation (Knight, 2007).

Toxicity: Poisoning in dogs generally occurs via ingestion of the plant or exposure to the eye. All parts of the plant especially stem and leaves are poisonous.

Clinical signs: Dogs and cats are the most affected animals. In the result of the chewing of stem or leaves of dumb cane, effects from mild local irritation to death may occur (Cortinovis and Caloni, 2017; Akça et al., 2014). Contents of the plant cause local irritations via inflammatory reaction. Edema in respiratory tract and obstructions may occur. After chewing the plant, clinical signs such as pain in the mouth, moderate swelling in the mouth and throat, hypertrophy in the tongue, edema and ulceration in the mouth mucosa, hypersalivation, dyspnea, odynophagia, difficulty chewing, hoarse voice, and vomiting occur (Knight, 2007). In severe cases, animals may die with dyspnea due to upper respiratory obstruction (Loretti et al., 2003). Cases mostly show mild clinical signs and may recover completely. Contact of the plant sap to the eye can lead to edema in the eye lids, inflammation in the cornea and the conjunctiva (Anadon et al., 2012), and temporary blindness from several hours to several days. Dumb cane with contents of calcium oxalate crystals can cause irritation in the gastrointestinal tract, acute hypocalcemia, acute tubular necrosis in the kidney, and multiple organ failure (Anon, 2007). Information has been obtained that child, at a 1 year and 11 months of age, chews dumb cane when presented to the hospital due to erythema and swelling in the lip (Akça, 2014). In dogs and cats, after exposure to the plant, gastric ulceration and obstruction in the respiratory tract have been reported (Müller et al., 1998; Peterson et al., 2009). Diagnosis is made by information that the owner gives and clinical signs.

Treatment: Treatment must be supportive including fluid therapy, and oxygen treatment. Measures should be taken for mouth mucosa and tongue swelling when ingested in excess amount of plant. Prognosis is usually good (Peterson et al., 2009).

\subsection{Chinaberry tree (Melia azedarach)} Characteristics and Resources: Melia azedarach (M. australis, $M$. japonia, $M$. sempervivens) are a plant of Meliaceae family, cultivated as ornamental plant all over the world, rapid grown up, and fall leaf in winter (Mendez et al., 2002; Tiwari and Sinha, 2010; Cortinovis and Caloni, 2017). Fruits are yellow when they are ripe (Cortinovis and Caloni, 2017). It is used for anthelmintic, tonic, antipyretic, antifungal and also alleviating of leprosy, eczema, and asthma (Phua et al., 2008). In southern Europe, it is grown as an ornamental tree along streets, and roadsides and around houses.

Toxic components: Tetranortriterpenes are important toxic components (Tiwari and Sinha, 2010). Toxic components of tree are tetranortriterpene neurotoxins of the cytotoxic limonoid class known as meliatoxins A1, A2, B1, and B2 in high level in fruits. These toxic components affect as enterotoxins and neurotoxins (Oelrichs et al., 1983). Alkaloids, flavonoids, limonoids, steroids and triterpenoids are also isolated from leaves and barks of tree (Ge et al., 2016; Pan et al., 2014). Other potentially toxic components comprise azadarin (alkaloid), meliotannic acid, benzoic acid, and resins such as azaridine, parisine, and 
margosinine (Plumlee, 2003). Action mechanism of meliatoxins is not well known. The toxicity of tree and its fruits has been demonstrated to vary due to environmental conditions according to growing area and stage of growth (Knight, 2007; Ferreiro et al.,

Table 1. Some important household plants leading to poisoning in dogs and cats

\begin{tabular}{|l|l|}
\hline Dieffenbachia spp. & Taxus baccata \\
\hline Lilium spp. & Hamerocallis fulva \\
\hline Aloe vera & Cannabis spp. \\
\hline African violet & Brunfelsia spp. \\
\hline Begonia & Melia azedarach \\
\hline Montera deliciosa & Digitalis spp. \\
\hline Euphorbia pulcherrima & Ilex aquifolium \\
\hline Ricinus communis & Convallaria majalis \\
\hline Narcissus spp. & Laburnum spp. \\
\hline Cyclamen spp. & Cassia spp. \\
\hline Azalea spp. & Hyacinthus orientalis \\
\hline Nerium oleander & Euphorbia spp. \\
\hline Spathiphyllum spp. & Nicotiana tabacum \\
\hline Lonicera spp. & Cestrum spp. \\
\hline Vitis spp. & Araceae spp. \\
\hline Allium spp. & \\
\hline
\end{tabular}

Toxicity: Poisoning related to chinaberry tree has been reported in horses, cattle, sheep, goats, pigs, dogs, rabbits, rats, guine pigs, and poultry (Cooper, 2007; Tiwari and Sinha, 2010; Cortinovis and Caloni, 2017). It is known by veterinary surgeons that chinaberry tree is toxic (Cortinovis and Caloni, 2013). Its fruits are highly toxic. Other leaves, stems, flowers are mildy toxic. Poisoning events are usually occurred in dogs. All parts of tree are toxic but poisoning usually occurs after fruits are ingested. Five or six fruits (less than $100 \mathrm{~g}$ ) at $0.6 \mathrm{~g} / \mathrm{kg}$ can cause poisoning (nausea, spasm and death) in small dogs.
Clinical signs: Clinical signs in domestic animals quickly occur and usually start several hours after ingestion (usually within 2-4 hours), and may be dominated as gastrointestinal and nervous system signs (Botha and Penrith, 2009; Ferreiro et al., 2010). Clinical signs related to gastrointestinal tract include anorexia, nausea, vomiting, constipation, diarrhea (frequently bloody), gastric pain, and colic. Clinical signs related to nervous system include excitement or weakness, convulsions, ataxia, paresis, and coma (Botha and Penrith, 2009; Ferreiro et al., 2010). Other signs are depression, 
bradycardia or cardiac arrest, collapse of circulatory system, congestion in the lungs, and dyspnea (Hare et al., 1998; Cortinovis and Caloni, 2017; Tiwari and Sinha, 2010). Death may be occurred 1 day after ingestion (Tiwari and Sinha, 2010). Clinical signs in humans are nausea, vomiting, diarrhea, thirst, perspiring, grinding of the teeth, drowsy, and colvulsions. Diagnosis is made by information that the owner gives and with clinical signs.

Treatment: Treatment is supportive care including stabilization of vital signs, maintaining a patent airway, oxygen supplementation, maintaining cardiovascular function, fluid and electrolyte administration, removing gastrointestinal plant materials via medical or operation, alleviating abdominal pain, and controlling nervous system signs (Poppenga, 2017).

Dog, Teckel breed, 4 years old, 8 kg weight, has been presented to the animal hospital tremors, and moderate limp in the hind leg. In clinical signs, abdominal pain has been determined and radiological examination has showed foreing radiodense bodies. Oral paraffin oil ( $6 \mathrm{ml} \mathrm{q} 8 \mathrm{~h}$ for 2 days) and carprofen ( $4 \mathrm{mg} / \mathrm{kg}$ daily and orally) have been administrated. After 2 days, increase in abdominal pain, depression, ataxia in the hind legs has been more evident. In the enterotomy, seeds of chinaberry tree (Melia azedarach) have been evacuated. Ringer's lactate fluid to treat dehydration, dexamethazone $(0.1 \mathrm{mg} / \mathrm{kg} /$ gün$)$ to alleviate pain and inflammation, phosphor and vitamin to stimulate nervous system (Catosal, $0.5 \mathrm{ml} / \mathrm{q} 24$ h, i.m., only once) have been administrated. Patient has fully recovered. Ataxia in the hind legs has been recovered after two months (Ferreiro et al., 2010).

\subsection{Castor Oil Plant (Ricinus communis)} Characteristics and resources: Castor oil plant is a flowering plant of Euphorbiaceae family, widespread grown all over the world, especially in tropical and temperate regions (Cortinovis and Caloni, 2017). This plant is grown widespread in Western and South Anatolia regions of our country. Flowers are head of the trunk and fruits are spiny. All parts of the plant, especially seeds, are toxic and rich in oil and ricin (Cortinovis and Caloni, 2017).

Toxic components: The compound responsible for poisoning is toxalbumin ricin with two A and B chains that are bound with disulfide bond. B chain is bound to the proteins containing galactoside on the cell surfaces and facilitates the entry of A chain to the cell cytosol, where ribosomes are rendered inactive and thus, protein synthesis is inhibited (Lord et al., 1994). Toxalbumin in the shell of fruits is a water soluble glycoprotein and is one of the most poisonous compounds among the compounds with plant origin. Besides toxic ricin, the plant includes piperidine alkaloid ricinine, and affects nerve receptors.

Toxicity: All animal species are highly sensitive to the toxic effects of ricin (Worbs et al., 2011), and this plant should be paid attention (Bradberry et al., 2003). This plant is also toxic in horses, usually in dogs, and ricin is one of the most toxic compounds among plant originated compounds. This plant contains ricin and piperidine alkaloid ricinine. Ricinine compound can cause neuromuscular weakness as a result of the effect on nerve receptors (Bailey, 2013).

Clinical signs: Poisoning with castor oil plant is usually associated with ingestion of seeds (Bailey, 2013). Signs occur with gastrointestinal inflammation and bleeding in the result of damage of cells of alimentary tract and severe irritation. In the event of poisoning of dogs, about $9 \%$ have died or euthanasia has been made. Clinical signs occur longer time or $8 \mathrm{~h}$ after ingestion of this plant and nausea, severe vomiting, 
anorexia, thirst, irritation of gastrointestanal system, abdomianl pain, bloody diarrhea, and tenesmus with rectal bleeding, fluid loss, and severe inflammation in the gastrointestinal system during postmortem period are usually seen. Weight loss, tremors, convulsions, dispnea, opisthotonus, coma and death occur. Increase in bleeding time, hypoproteinemia, and cyanosis occur (Albretsen et al., 2000; Anadon et al., 2012; Doan, 2004). In addition, convulsions and tachycardia may be seen up to death time (Audi et al., 2005; Soto-Blanco et al., 2002).

Treatment: Induction of emesis can be helpful early after ingestion of castor bean with use of hydrogen peroxide $3 \%, 1$ to 5 $\mathrm{ml} / \mathrm{kg}$. In addition, activated charcoal and cathartic (magnesium sulphate 5-25 g or sorbitol $3 \mathrm{ml} / \mathrm{kg}$ ) can be given unless animal has diarrhea. Gastrointestinal protectants such as sucralfate should be used as needed. Fluid therapy with balanced electrolyte solutions is given and diazepam can be given for seizures. After vomiting is controlled, soft, bland diet is given for one to four days (Poppenga, 2017; Albretsen et al., 2000).

\subsection{Poinsettia (Euphorbia pulcherrima)} Characteristics and resources: Poinsettia (Euphorbia spp.) in Euphorbiaceae family is a small shrub widely cultivated in tropical regions. This plant grows up to $30-40 \mathrm{~cm}$. It is widely used as indoor ornamental plant and using of it as ornamental plants in parks and along streetsides increases day by day because of its beatiful view (Cortinovis and Caloni, 2017).

Toxic components: Poinsettia has milky sap. Toxic ingredients present in milky sap are responsible from irritation and this sap contains diterpenoid euphorbol esters and steroids with saponin-like properties (Botha and Pentrith, 2009; Gwaltney-Brant, 2013).

Toxicity: Many cases have been reported to have no clinical signs when this plant is ingested. Intoxications occur when the plant produce red bracts. All parts of the plant have toxic effects and have moderate toxic effects in dogs and cats (Anon, 2020).

Clinical signs: Poisoning by poinsettia in dogs and cats may occur. After ingestion of the plant, licking the lip, irritation of the face, mouth, lips and nare, hypersalivation, vomiting and rarely diarrhea in dogs and cats are seen (Anon, 2020; Botha and Penrith, 2009; Campbell and Chapman, 2000). Contact to the skin results in irritation, erthema and itching of the skin. Contact of the sap to the eye may cause redness of the eye, conjunctivitis and lacrimation (Gwaltney-Brant, 2013). Death has occurred with severe gastrointestinal disorder and fever when large amounts of plant are ingested. Other signs are vomiting, hypersalivation, diarrhea, abdominal distention, and fever.

Treatment: Medical treatment is based on the exposure amount of toxic components. Treatment may include gastrointestinal decontamination, fluid therapy, and antihistaminic administration (Anon, 2020).

\subsection{Daffodil (Narcissus spp.)}

Characteristics and resources: This plant that blooms in the spring is perennial and is grown from a bulb of daffodil plant. It is known that ingestion of daffodil bulbs in Amarylidaceae family causes poisoning. It leads to persistent intoxication in humans and animals (Kretzing et al., 2011). Their stems contain clear viscous sap. It has small fruits, filled with black seeds, and wrapped with green capsule (Campbell and Chapman, 2000).

Toxic components: The parts of the plant related to poisoning contain alkaloids and glycosides as toxic components. These components are present in high concentrations in the bulb of the plant. Alkaloids responsible from the toxic effects 
are narcissine, narciclasine, galanthamine, and lycorine in high amounts. They contain calcium oxalate crystals (Severino, 2009; Kızıl and Çiftçi, 2018). Glycosides of this plant include scillitoxin. Lycorine and other alkaloids cause irritation, emesis and purgative effects and calcium oxalate crystals cause mechanical irritation (Campbell and Chapman, 2000).

Toxicity: Poisoning cases related to daffodil generally result from ingestion of the plant and drinking water in the plant container (Severino, 2009). In dogs, poisoning cases frequently occur because they chew and consume (Campbell and Chapman, 2000; Saxon-Bury, 2004). Several plant bulbs (15 g plant bulb) is fatal to a small animal kept in home. Severe vomiting and weakness have occurred in a Cocker Spaniel breed dog $1 \mathrm{~h}$ after ingesting 12 the head of plant flower and then dog has recovered without any treatment. Within $3 \mathrm{~h}$ of ingestion of unknown amounts of plant bulb, in a Golden Retriever dog, 8 months old, weakness, mucosal paleness, tachycardia, decrease in body temperature, hyperglycemia and vomiting have occurred. This dog has recovered with fluid, dexamethazone, insulin, adrenaline and diazepam administration. In 6 years old cross-bred dog, daffodil toxicity has occurred due to ingestion of bulbs. This dog had showed severe abdominal pain, hypersalivation, pale mucous membranes, and diarrhea. Serum biochemistry analysis has revealed increased urea and creatinine. The animal has been euthanased at the owner's request (Campbell and Chapman, 2000).

An adult cat, 2 years old, has been presented to the animal hospital due to weakness and vomiting after ingestion of dried daffodil stems (Narcissus spp.). Hypotension, hypothermia, bradycardia, and fluid loss have been determined. Complete blood count had normal and increase in urea and glucose, decrease in sodium, potassium and chloride concentrations in serum biochemical examination has been determined (Saxon-Buri, 2004).

In London, Veterinary Poisons Information Service has examined cases related to daffodil ingestion. It was reported that of 4 poisoning cases, 1 case died and 1 case was euthanized. Important clinical signs are vomiting, diarrhea, weakness, depression, hypothermia, hypotension, bradycardia, abdominal pain, hyperglycemia, and fluid (Campbell and Chapman, 2008). In humans, clinical signs are nausea, vomiting, diarrhea, and vertigo. Irritation and skin inflammation occurs in people collecting daffodil due to skin contact of daffodil. Recent studies have demonstrated that oxalate crystals in the plant stems cause skin lesions (Chiu et al., 1992).

Clinical signs: Clinical signs are vomiting, diarrhea, abdominal pain, anorexia, hypersalivation, and restlessness (Fitzgerald, 2010). Ingestion of high amounts may cause ataxia, lethargy, hypothermia, bradycardia, hypotension, and depression. About $15 \mathrm{~g}$ plant bulb can cause death in dogs (Severino, 2009). Clinical signs occur within $15 \mathrm{~min}$ to $24 \mathrm{~h}$. In the event of ingestion of high amounts, severe ataxia, collapse, hypothermia, arrythmia, severe abdominal pain, hyperglycemia, fluid loss, tremors, convulsions occur. In the case of contact with the plant sap, skin itching and eczema occur. Diagnosis is made based on that the owner gives information and clinical signs (Campbell and Chapman, 2000).

Treatment: Supportive care is required including stabilization of vital signs, maintaining a patent airway, maintaining cardiovascular function, fluid and electrolyte administration, gastrointestinal decontamination, alleviating abdominal pain, and controlling nervous system signs (Poppenga, 2017). If animal ingests daffodil and does not vomit, then emesis can be induced. If persistent emesis occurs, then 
antiemetic treatment is given. A dog has been treated using fluid, dexamethazone, insulin, adrenaline and diazepam (Campbell and Chapman, 2000). A cat has been treated using fluid therapy, atropin, dexamethazone, and wrapping to the warm towel (SaxonBuri, 2004).

\section{Conclusions and proposals}

Considering toxicity features of the plants while in areas around parks and gardens, and houses and yards, landscaping will be performed, in order to inform the user, labels identifying severity of toxicity of the plant, its effects, its parts should be attacted on plants in plantation, nursery gardens, flower shops, and other selling places, and this condition should be necessary. The owners of animals, local authorities, landscape architects, other related occupation groups and their associations, public and private enterprises, and veterinary surgeons should recognize these plants and know prevention measures to them. In addition, veterinary surgeons should know treatments choices in the case of animal poisoning with these poisonous plants.

In the case of poisoning with plants, recognition of the plant, identification of toxic components, and diagnosis of affected system are highly beneficial for treatment. In the event of plant poisonings of dogs and cats, if no antidote, supportive care is necessary by identifying treatment regime with considering toxicokinetics and toxicodynamics of toxic components. In addition, increase of physical activity and increase of time of playing game, decrease of boring, observing them and spending more time with them may decrease tendencies to plant eating (Fitzgerald, 2010).

\section{Acknowledgments}

\section{Conflict of Interest}

No conflict of interest was reported by the authors.

\section{References}

1. Albretsen, J.C., Gwaltney-Brant, S.M., and Khan, S.A., 2000. Evaluation of castor bean toxicosis in dogs: 98 cases. Journal of the American Animal Hospital Association, 36 (3), 229-233. DOI number: 10.5326/15473317-36-3-229

2. Akça, H., Polat, E., Tuygun, N., Gürcan Kaya, N., ve Demir Karacan, C., 2014. Evdeki Tehlike: Difenbahya. Journal of Academic Emergency Medicine Case Reports/Akademik Acil Tip Olgu Sunumlar1 Dergisi, 5 (4), 107-109. DOI number: 10.5152/jaemcr.2014.47568

3. Anadón, A., Martínez-Larrañaga, M.R., and Castellano, V., 2012. Poisonous plants of Europe. In: Gupta RC, editor. Veterinary Toxicology: Basic and Clinical Principles. 2nd ed. San Diego: Elsevier.

4. Anon, 2007. T.C. Sağlık Bakanlığı, Refik saydam Hıfzıssıhha Merkezi Başkanlığı, Hıfzıssıhha Mektebi Müdürlüğü, Birinci Basamağa Yönelik Zehirlenmeler Tanı ve Tedavi Rehberleri, Bitkilerle Zehirlenmeler, 712, 171-3.

5. Anon, 2020. "Poinsettia poisoning in dogs". https://wagwalking.com/condition/poinsettiapoisoning. Access Date: 04.02.2020.

6. Audi, J., Belson, M., Patel, M., Schier, J., and Osterloh, J., 2005. Ricin poisoning: A comprehensive review. Journal of the American Medical Association, 294 (18), 2342-2351. DOI number: 10.1001/jama.294.18.2342

7. Bradberry, S.M., Dickers, K.J., Rice, P., Griffiths, G.D., and Vale, J.A., 2003. Ricin poisoning. Toxicological Reviews, 22 (1), 65-70. DOI number: 10.2165/00139709-200322010-00007

8. Bailey, Jr EM., 2013. Ricin. In: Petersen ME, Talcott PA, editors. Small Animal Toxicology. 3rd ed. St. Louis: Saunders.

9. Botha, C.J., and Penrith, M.L., 2009. Potential plant poisonings in dogs and cats in southern Africa. Journal of the South African Veterinary Association, 80 (2), 63-74. DOI number: 10.4102/jsava.v80i2.173.

10. Campbell, A., and Chapman, M., 2000. Handbook of poisoning in dogs and cats. London: Blackwell Science.

11. Campbell, A., and Chapman, M., 2008. Handbook of poisoning in dogs and cats: John Wiley \& Sons.

12. Chiu, K., Lee, Y., and Yung, K., 1992. Bioactive substances from the Chinese daffodil, Narcissus tazetta. Phytotherapy Research, 6 (5), 231-236.

13. Cooper, R.G., 2007. Poisoning in ostriches following ingestion of toxic plants-field observations. Tropical Animal Health and Production, 39 (6), 439-442. DOI number: $10.1007 / \mathrm{s} 11250-007-9044-\mathrm{y}$. 
14. Cortinovis, C., and Caloni, F., 2013. Epidemiology of intoxication of domestic animals by plants in Europe. Veterinary Journal, 197 (2), 163-168. DOI number: 10.1016/j.tvj1.2013.03.007.

15. Cortinovis, C., and Caloni, F., 2017. Plants Toxic to Farm and Companion Animals. Page: 107-134.

16. Doan, L.G., 2004. Ricin mechanism of toxicity, clinical manifestation, and vaccine development. Clinical Toxicology, 42 (2), 201-208. DOI number: 10.1081/clt-120030945.

17. Ferreiro, D., Orozco, J.P., Mirón, C., Real, T., Hernández-Moreno, D., Soler, F., Perez-Lopez, M., 2010. Chinaberry tree (Melia azedarach) poisoning in dog: a case report. Topics in Companion Animal Medicine, 25 (1), 64-67. DOI number: 10.1053/j.tcam.2009.07.001

18. Fitzgerald, K.T., 2010. Lily toxicity in the cat. Topics in Companion Animal Medicine, 25 (4), 213-217. DOI number: 10.1053/j.tcam.2010.09.006

19. Ge, J-J., Wang, L-T., Chen, P., Zhang, Y., Lei, X-X., Ye, X-X., 2016. Two new tetracyclic triterpenoids from the barks of Melia azedarach. Journal of Asian Natural Products Research, 18 (1), 20-25. DOI number: 10.1080/10286020.2015.1124866

20. Gwaltney-Brant, S.M., 2013. Christmastime plants. In: Petersen ME, Talcott PA, editors. Small Animal Toxicology. 3rd ed. St. Louis: Saunders.

21. Hare, W., Garland, T., and Barr, A., 1998. Chinaberry (Melia azedarach) poisoning in animals. Toxic Plants and Other Natural Toxicants. CAB International, Wallingford, 514-516.

22. Kızıl, Ö., and Çiftçi, Ü., 2018. Kedi ve köpeklerde bitkisel zehirlenmeler. Firat University Journal of Health Sciences (Veterinary), 32 (1), 69-73.

23. Knight, A.P., 2007. A guide to poisonous house and garden plants. Jackson: Teton, NewMedia.

24. Kretzing, S., Abraham, G., Seiwert, B., Ungemach, F.R., Krugel, U., and Regenthal, R., 2011. Dosedependent emetic effects of the Amaryllidaceous alkaloid lycorine in beagle dogs. Toxicon, 57 (1), 117-124. DOI number:10.1016/j.toxicon.2010.10.012

25. Lord, J.M., Roberts, L.M., and Robertus, J.D., 1994. Ricin: structure, mode of action, and some current applications. FASEB Journal, 8 (2), 201-208.

26. Loretti, A.P., da Silva Ilha, M.R., and Ribeiro, R.E., 2003. Accidental fatal poisoning of a dog by Dieffenbachia picta (dumb cane). Veterinary Human Toxicology, 45 (5), 233-239.

27. Mahdi, A., and van der Merwe, D., 2013. Dog and cat exposures to hazardous substances reported to the Kansas State Veterinary Diagnostic Laboratory: 2009-2012. Journal of Medical Toxicology, 9 (2), 207-211. DOI number:10.1007/s13181-013-0289-8

28. Méndez, C., Aragão, M., Fabiana, E., Riet-Correa, F., and Juan Gimeno, E., 2002. Experimental intoxication by the leaves of Melia azedarach (Meliaceae) in cattle. Pesquisa Veterinária Brasileira, $22(1), 19-24$
29. Müller, N., Glaus, T., and Gardelle, O., 1998. Extensive stomach ulcers due to Dieffenbachia intoxication in a cat. Tierarztl Prax Ausg K Kleintiere Heimtiere, 26, 404-407.

30. Pan, X., Matsumoto, M., Nishimoto, Y., Ogihara, E., Zhang, J., Ukiya, M., Tokuda, H., Koike, K., Akihisa, M., and Akihisa, T., 2014. Cytotoxic and nitric oxide production-inhibitory activities of limonoids and other compounds from the leaves and bark of Melia azedarach. Chemistry and Biodiversity, 11 (8), 11211139. DOI number: $10.1002 / c b d v .201400190$

31. Panter, K.E., Welch, K.D., Gardner, D.R., and Green, B.T., 2013. Poisonous plants: effects on embryo and fetal development. Birth Defects Research Part C Embryo Today, 99, 223-234.

32. Peterson, K., Beymer, J., Rudloff, E., and O'Brien, M., 2009. Airway obstruction in a dog after Dieffenbachia ingestion. Journal of Veterinary Emergency Critical Care (San Antonio), 19 (6), 635639. DOI number: $10.1111 / \mathrm{j} .1476$ 4431.2009.00486.x

33. Phua, D.H., Tsai, W.J., Ger, J., Deng, J.F., and Yang, C.C., 2008. Human Melia azedarach poisoning. Clinical Toxicology, 46 (10), 1067-1070. DOI number:10.1080/15563650802310929

34. Plumlee, K., 2003. Clinical Veterinary ToxicologyE-Book: Elsevier Health Sciences.

35. Poppenga, R.H., 2017. Chapter 19. Toxicological emergencies. Lesley G. King, Amanda Boag (eds). BSAVA Manual of Canine and Feline Emergency and Critical Care, Second edition, p. 278-294.

36. Oelrichs, P.B., Hill, M.W., Vallely, P.J., MacLeod, J.K., and Molinski, T.F., 1983. Toxic tetranortriterpenes of the fruit of Melia azedarach. Phytochemistry, 22 (2), 531-534.

37. Severino L., 2009. Toxic plants and companion animals. CAB Reviews, 4, 1-8.

38. Saxon-Buri, S., 2004. Daffodil toxicosis in an adult cat. Canadian Veterinary Journal, 45 (3), 248-250.

39. Soto-Blanco, B., Sinhorini, I.L., Gorniak, S.L., and Schumaher-Henrique, B., 2002. Ricinus communis cake poisoning in a dog. Veterinary Human Toxicology, 44 (3), 155-156.

40. Sueda, K.L.C., Hart, B.L., and Cliff, K.D., 2008. Characterisation of plant eating in dogs. Applied Animal Behaviour Science, 111 (1-2), 120-132.

41. Tiwari, R.M., and Sinha,M., 2010. Veterinary Toxicology. Oxford Book Company, Jaipur, India.

42. Worbs, S., Köhler, K., Pauly, D., Avondet, M.A., Schaer, M., Dorner, M.B., and Dorner, B.G., 2011. Ricinus communis intoxications in human and veterinary medicine-a summary of real cases. Toxins, 3 (10), 1332-1372. DOI number: 103390/toxins3101332

43. Yılmaz, H., Akpınar, E., and Yılmaz, H. 2006. Peyzaj mimarlığı çalışmalarında kullanılan bazı süs bitkilerinin toksikolojik özellikleri. Süleyman Demirel Üniversitesi Orman Fakültesi Dergisi, 7 (1), 82-95. 